\title{
Clear-cut difference in the rearrangement of 1-bromo-2-(2-phenyl- 3-butenyl)benzene under anionic or radical conditions
}

\author{
Céline Reynaud, ${ }^{a}$ Hassan Hazimeh, ${ }^{\text {a Jean-Marc Mattalia, }{ }^{\text {a* }} \text { Caroline Marchi-Delapierre, }}{ }^{\text {b }}$ \\ and Michel Chanon ${ }^{a}$ \\ ${ }^{a}$ Université Paul Cézanne, iSm2, UMR-CNRS 6263, Campus Scientifique de Saint-jérôme, \\ Service 551, 13397 Marseille Cedex 20, France \\ ${ }^{b}$ Université Joseph Fourier, Laboratoire de Chimie et Biologie des Métaux, UMR-CNRS 5249, \\ IRTSVCEA-Grenoble, 38054 Grenoble Cedex, France \\ E-mail: jean-marc.mattalia@univ-cezanne.fr
}

\begin{abstract}
The $o$-(3-butenyl)phenyl system bearing a phenyl group on the 2-position of the side chain was studied as a potential mechanistic probe for distinguishing between radical and carbanion intermediates. The $\mathrm{Bu}_{3} \mathrm{SnH}$ reduction of 1-bromo-2-(2-phenyl-3-butenyl)benzene, 4, yields mainly the 1,5-cyclization product, $\mathbf{6}$, with a preference for the trans- isomer. Treatment of 4 with $\mathrm{Mg}$ or $t$-BuLi leads to double-bond isomerization and yields $(E)$-1,2-diphenyl-2-butene, 8 , along with 3,4-diphenyl-1-butene, 5.
\end{abstract}

Keywords: Radical probe, carbanion, rearrangement, proton transfer, cyclization

\section{Introduction}

Mechanistic studies of chemical and biochemical processes often include reactions of radical probe substrates. Our interest in the mechanism of formation of Grignard reagents and homogeneous versus heterogeneous electron transfers focused our attention on 1-bromo-2-(3butenyl)benzene $1{ }^{1-4}$ Cyclization of $o$-(3-butenyl)phenyl radical $2 \mathbf{r}\left(k_{c y}=5 \times 10^{8} \mathrm{~s}^{-1}, 30{ }^{\circ} \mathrm{C}\right)$ to 1 methylindanyl radical $3 \mathbf{r}$ and related rearrangements have been used to detect radical intermediates in several reactions. ${ }^{5-8}$ However, cyclization of the $o$-(3-butenyl)phenyl anion 2c has to be considered (Scheme 1). The reaction of 1 with 2 equiv of $n$-BuLi yields $42 \%$ of cyclization product after 5 minutes at room temperature. ${ }^{9}$ This anionic rearrangement was confirmed later by a series of electrochemical experiments. ${ }^{10}$ Consequently, tests using the radical probe 1 have to be carried out under conditions where the anion does not cyclize, at low temperature, or by increasing the proton-donating ability of the solvent with adequate additives. $^{3,10,11}$ This mechanistic drawback is not specific to radical probe 1 . Several probes based on the cyclopropylcarbinyl radical ring-opening have been applied in studies of P-450 
oxidation of hydrocarbons. ${ }^{12}$ However, the corresponding carbocations lead to the same rearranged products.

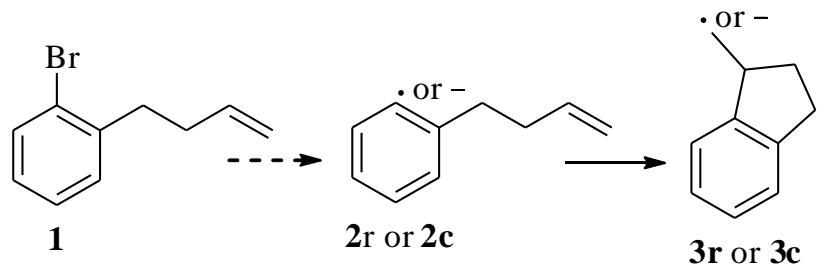

\section{Scheme 1}

Newcomb et al., by substituting the cyclopropyl ring with appropriate substituents, designed a hypersensitive mechanistic probe to differentiate between radical and carbocation intermediates. ${ }^{13,14}$ In mechanistic studies involving 6-halo-1-heptenes, this information was provided by the proportion of cis- and trans-isomers of the 1,2-dimethylcyclopentane obtained. The 6-hepten-2-yl radical cyclizes with a preference for the cis-stereochemistry while the corresponding organolithium gives predominantly the trans- isomer. ${ }^{15-18}$ Cohen et al. used such cis-/trans- ratios of cyclization products to show that unsaturated alkylzinc iodides cyclize by a radical rather than a polar mechanism. They found that probably all of the organozinc cyclizations are radical chain reactions initiated by traces of oxygen. ${ }^{19}$ These findings appear as an additional warning against deceptive rearrangements observed with radical probes. ${ }^{20}$

The aim of our work was to design a new radical probe for distinguishing between $o$-(3butenyl)phenyl radical $2 \mathbf{r}$ and the corresponding carbanion $2 \mathbf{c}$ intermediates. On the basis of the results obtained with 6-halo-1-heptenes, our probe design was first based on the simple idea that substitution on the allylic position of the butenyl chain with a phenyl group could induce a difference in the stereochemistry of cyclization according to the nature of the intermediate.

\section{Results and Discussion}

The radical probe 4 was prepared by the reaction of cinnamyl bromide with mechanically activated $\mathrm{Mg}$, which yields cinnamylmagnesium bromide, ${ }^{21}$ then reaction of this Grignard reagent with 2-bromobenzyl bromide which occurs with an allylic rearrangement ${ }^{22}$ yields 1-bromo-2-(2-phenyl-3-butenyl)benzene 4 in 53\% isolated yield (Scheme 2).

The radical chemistry of 4 was studied under $\mathrm{Bu}_{3} \mathrm{SnH}$ reduction conditions. ${ }^{23}$ The reaction of 4 with $\mathrm{Bu}_{3} \mathrm{SnH}(2.4$ equiv, $0.25 M$ ) in refluxing benzene gave the linear product 5 (7\% relative yield), the two five-membered cyclized products $6(84 \%$, trans/cis $=88 / 12$, GC), and 2phenyltetralin 7 (9\%). From GC analysis, 5, 6 and 7 accounted for $c a 90 \%$ of the total product mixture (Scheme 3). Aryl radicals are aggressive hydrogen atom abstractors and 1,4-hydrogen atom transfer would lead to a thermodynamically stabilized radical. ${ }^{24}$ This situation is 
reminiscent of the formation of pentadienyl radicals. ${ }^{25}$ Nevertheless, in contrast to 1,5-hydrogen transfer, ${ }^{26} 1,4$-hydrogen atom transfer is less frequently observed ${ }^{27,28}$ and such a competition with cyclization was neglected here.

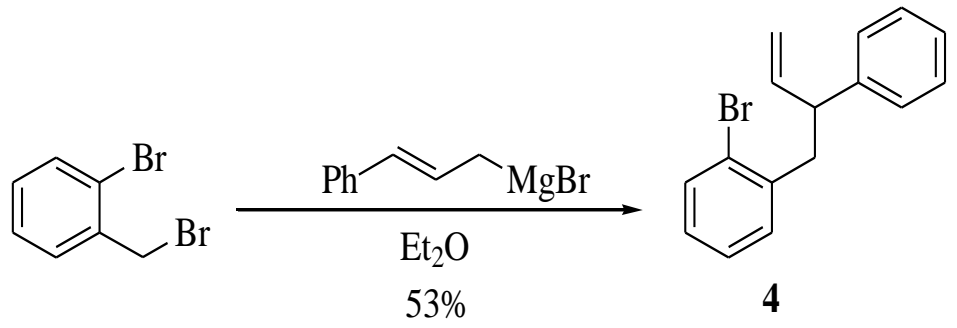

\section{Scheme 2}

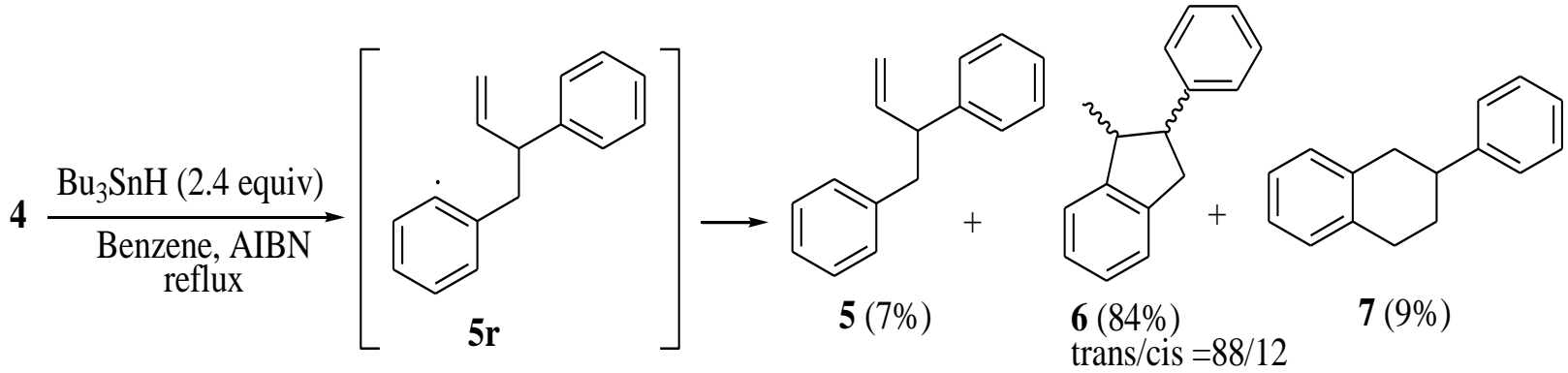

\section{Scheme 3}

These results conform to Beckwith's studies on the $o$-(3-butenyl)phenyl radical bearing substituents on the 2-position of the butenyl chain. These radicals show a preference for the formation of trans- disubstituted products and give also small amounts of 6-membered rings (endo products). ${ }^{29,30}$ With a larger excess of $\mathrm{Bu}_{3} \mathrm{SnH}$ ( 5 equiv., $0.46 \mathrm{M}$ ) the ratio 5/6/7 becomes $15 / 77 / 8$. The application of the steady-state theory shows that when $\mathrm{Bu}_{3} \mathrm{SnH}$ is in large excess, $\Sigma k_{c}=k_{H}\left[\mathrm{Bu}_{3} \mathrm{SnH}\right][\mathbf{C}] /[\mathbf{U}]$. The quantities $[\mathbf{C}]$ and $[\mathbf{U}]$ are the final concentrations of cyclized and uncyclized products, respectively, and $\Sigma k_{c}$ is the sum of the rate constants for cyclization. ${ }^{31}$ The value $k_{H}$ is the rate constant for the reaction of the aryl radical with $\mathrm{Bu} 3 \mathrm{SnH}$. Taking $k_{H}=$ $10^{9} \mathrm{~s}^{-1}\left(80{ }^{\circ} \mathrm{C}\right),{ }^{5}$ cyclization of radical $5 \mathrm{r}$ occurs with a rate constant $\Sigma k_{c}$ of about $2.6 \times 10^{9} \mathrm{~s}^{-1}$ at $80{ }^{\circ} \mathrm{C} .{ }^{32}$ This value is slightly higher than the previous determination of the rate constant for cyclization of $2 \mathbf{r}\left(k_{c}=10^{9} \mathrm{~s}^{-1}, 80{ }^{\circ} \mathrm{C}\right) .{ }^{5,6,29,31}$ A solution of benzene, radical probes 1 ( 1 equiv., $0.05 M), 4$ ( 1 equiv., $0.05 M), \operatorname{AIBN}\left(0.19\right.$ equiv) and an excess of $\mathrm{Bu}_{3} \mathrm{SnH}(0.95 \mathrm{M}$, added last) was heated under reflux for $5 \mathrm{~h}$. After work up, we examined the ratios $[\mathbf{C}] /[\mathbf{U}]$ for each structure. These ratios were respectively 61/39 and 73/27 for $\mathbf{1}$ and 4. Assuming that $k_{H}$ has the same value for alkenylphenyl radicals $\mathbf{2 r}$ and $\mathbf{5 r}$, we confirm that $\mathbf{5 r}$ cyclizes faster than $\mathbf{2 r}$. This rate-enhancing effect of the phenyl group was expected. Beckwith, in the same way, found an 
increase of $\Sigma k_{c}$ when the 3-butenyl chain was substituted with a methyl or an ester group on the 2-position. ${ }^{29}$

The carbanion chemistry of $\mathbf{4}$ was first studied under metal-halogen exchange reaction conditions. The reaction of 4 with $t$-BuLi (2.2 equiv.) in THF generates, after quenching with water, a mixture of hydrocarbons 5 and $\mathbf{8}$ in a ratio 5/8 =34/66 (Scheme 4). No cyclized product 6 was formed $(<1 \%)$. Instead, double bond isomerization takes place, which is in surprising comparison with the cyclization observed with the aryllithium reagent formed from $\mathbf{1}$. This migration is reminiscent of the results described by Wilson et al., ${ }^{33}$ in which reaction of 3,4diphenyl-1-butene, $\mathbf{5}$, at $0{ }^{\circ} \mathrm{C}$ with 1 equiv. of $n$-BuLi in a hexane/THF mixture yields, after quenching, $78 \%$ of $\mathbf{8}$ and $17 \%$ of the starting derivative, $\mathbf{5}$.

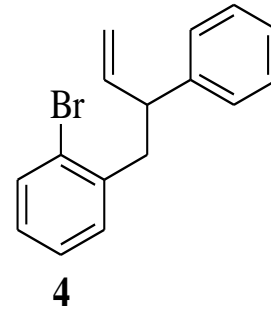

1) $t$-BuLi, THF $-78^{\circ} \mathrm{C}, 15 \mathrm{~min}$

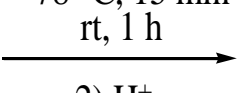

2) $\mathrm{H}^{+}$

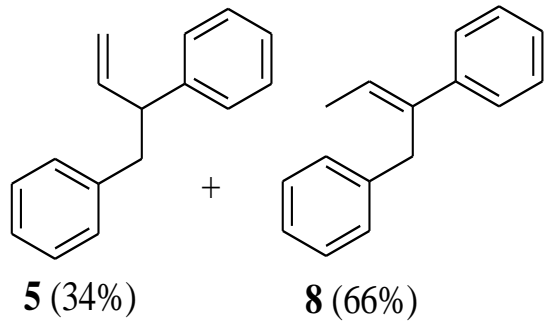

\section{Scheme 4}

The lithium-halogen exchange is an extremely fast process. Coupling products may be avoided by the use of two equivalents of $t$-BuLi. The second equivalent reacts rapidly with the $t$-BuBr formed, even at very low temperature, to give 2-methylpropene, 2-methylpropane and lithium halide. ${ }^{34}$ Several reports in the literature propose that alkyllithium compounds react faster with the $\mathrm{C}$-halogen bond than with acidic hydrogens. ${ }^{35-39}$ However the interpretation of this kind of competition can be far from straighforward. ${ }^{40}$ Under our reaction conditions, the total conversion of 4, and the low yields of incorporation of the $t$-Bu group observed $(\leq 1-20 \%$, see the Experimental Section) suggest that the excess of $t$-BuLi mainly quenches the $t$-BuBr formed, rather than deprotonating the allylic position. The formation of the rearranged product $\mathbf{8}$ could then be explained by an intramolecular 1,4-proton transfer leading to the delocalized carbanion 8Li (Scheme 5). Previous work proposes that such a proton transfer leading to an allyllithium intermediate could compete effectively with the cyclo-isomerization of an aryllithium. ${ }^{41}$ Intramolecular 1,4-proton transfer was also observed in the 5-hexenyl anion so that, under favorable conditions, the 5-hexenyl probe detects both alkyl radical and anion intermediates. ${ }^{42}$ Intramolecular proton transfers can be very fast, the proximity of reactive centers and the angle of attack playing an important role. ${ }^{43,44}$ 


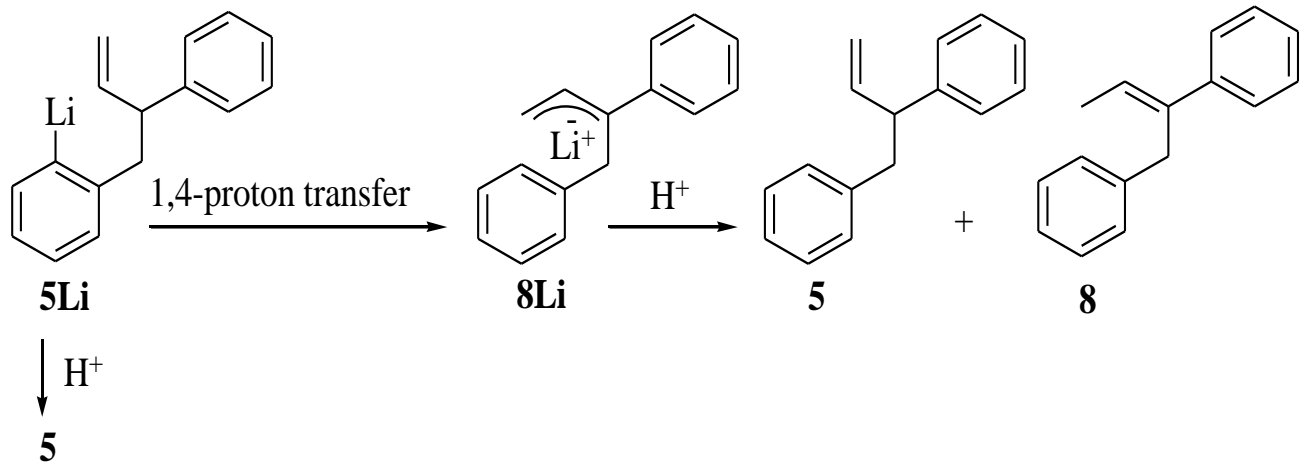

\section{Scheme 5}

Another way of generating carbanionic species was to study the reaction of 4 with $\mathrm{Mg}$. This reaction, in THF at room temperature, yields a mixture of $\mathbf{5}$ and $\mathbf{8}$ in a ratio of $\mathbf{5 / 8}=91 / 9$ (Scheme 6). No cyclized product 6 was formed $(<1 \%)$. In a series of works, Bickelhaupt's group showed $^{45-48}$ that the reaction of aryl halides with magnesium involves reactive aryl carbanion intermediates whose presence is evidenced by well identified by-products formed in yields of 4$85 \%$. The detailed interpretation of these results involves an aryl bromide radical anion whose cleavage provides an aryl radical which is reduced extremely rapidly into a carbanion. Combination of this carbanion with $\mathrm{MgBr}^{+}$leads to the Grignard reagent. ${ }^{49}$ The productdistribution depends on the rate of the reaction trapping the carbanion versus the barrier to the association of the carbanion with $\mathrm{Mg}^{\mathrm{II}} \cdot{ }^{50}$ Such competition, applied to the reaction of $\mathbf{4}$, is indicated in Scheme 6.

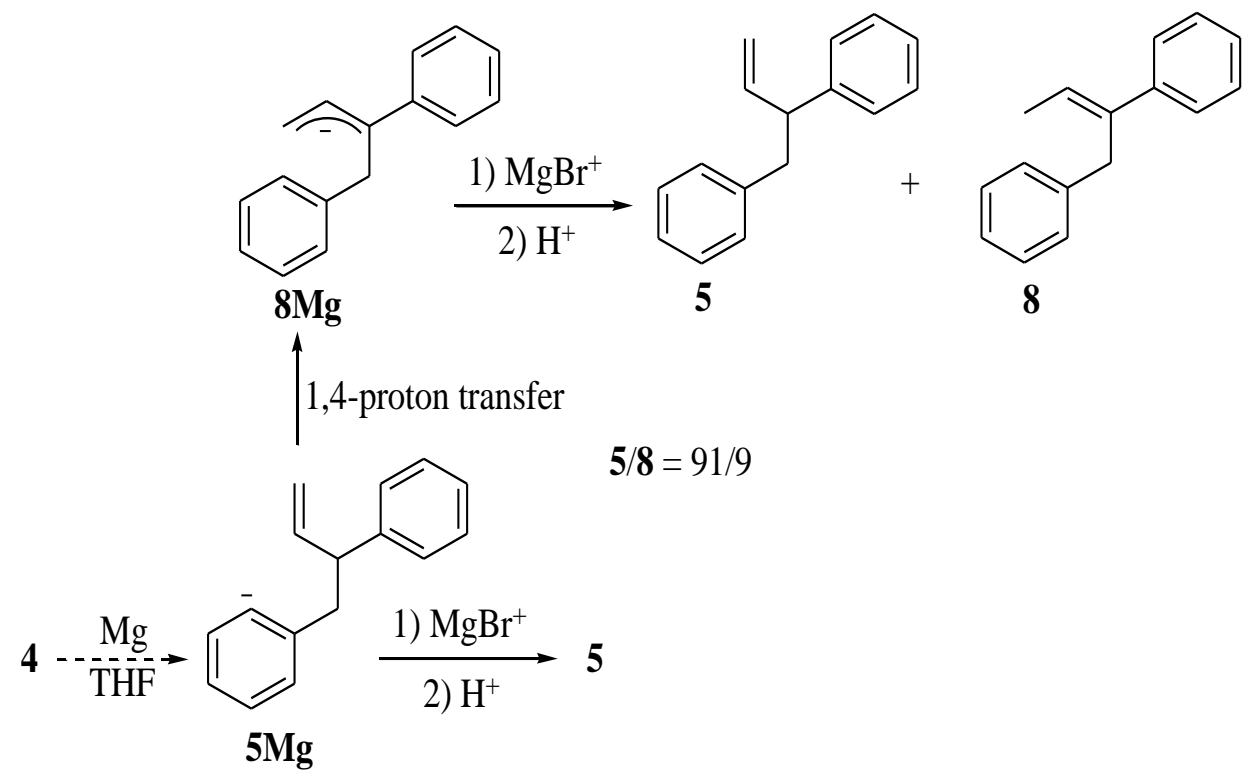

\section{Scheme 6}


Thus, considering Bickelhaupt's works, the rearranged product $\mathbf{8}$ would originate from a carbanion intermediate rather than the Grignard reagent itself. In both cases, this experiment indicates that the aryl carbanion species formed from $\mathbf{4}$ lead to the rearranged product 8 .

\section{Conclusions}

These results show that the radical probe derived from $\mathbf{4}$ behaves in a specific way. The presence of the phenyl ring in the $\alpha$-position to the exocyclic unsaturation increases considerably the acidity of the proton $\alpha-$ to this double bond. As a consequence, the rate of proton abstraction becomes higher than the rate of cyclization of the aryl carbanion. Under such conditions, the use of probe 4 to distinguish between radical and carbanionic route would be based directly on the nature of the formed products rather than on subtle stereochemical difference in yield of cyclized products. This work opens the way to a new family of radical probes designed for the study of reactions where carbanions and radicals are possibly involved.

\section{Experimental Section}

General. Diethyl ether, THF and benzene were dried over sodium-benzophenone and distilled from blue-purple solutions prior to use. $\mathrm{Bu}_{3} \mathrm{SnH} 97 \%$ (Aldrich), $t$-BuLi $1.5 \mathrm{M}$ in pentane (Acros) and magnesium turnings (Aldrich, 99.98\%) were used as received. Petroleum ether $40-65{ }^{\circ} \mathrm{C}$ and pentane for liquid phase chromatography were distilled prior to use. Thin-layer chromatography was performed using Merck silica gel $60 \mathrm{~F}_{254}$ plates. Column chromatography was performed using Merck silica gel (230-400 mesh). Separations were monitored by both TLC and GC. $\mathrm{AgNO}_{3}$-impregnated silica gel: in a flask equipped with a magnetic stirrer was introduced $\mathrm{AgNO}_{3}(2.5 \mathrm{~g})$ and $\mathrm{CH}_{3} \mathrm{CN}(150 \mathrm{~mL})$. After stirring in the dark $(10 \mathrm{~min})$ silica-gel $(50 \mathrm{~g})$ was added. The mixture was stirred 2 hours in the dark and then the solvent was evaporated. Drying was achieved overnight in an oven. The column was performed in the dark. Gas chromatography analyses were performed using a BPX5 capillary column (SGE, $25 \mathrm{~m}, 0.22 \mathrm{~mm}$ internal diameter) with helium as carrier gas and a flame ionization detector. The following temperature programs were used: injector : $280{ }^{\circ} \mathrm{C}$; detector: $250{ }^{\circ} \mathrm{C} ; 150{ }^{\circ} \mathrm{C}(3 \mathrm{~min})$ to $250{ }^{\circ} \mathrm{C}(5 \mathrm{~min})$ at 5 ${ }^{\circ} \mathrm{C} \min ^{-1}$ or $80{ }^{\circ} \mathrm{C}$ to $250{ }^{\circ} \mathrm{C}(5 \mathrm{~min})$ at $5{ }^{\circ} \mathrm{C} \mathrm{min}{ }^{-1}$. We assumed that response factors were similar for isomers. If necessary, the area integrations were corrected using the Effective Carbon Number. ${ }^{51}$ GC-MS (70 eV) analyses were performed using a HP5 MS capillary column (30 m, $0.25 \mathrm{~mm}$ i.d.) with helium as carrier gas. The following program temperature was used: injector : $280{ }^{\circ} \mathrm{C}$; interface: $280{ }^{\circ} \mathrm{C}$; $150{ }^{\circ} \mathrm{C}(3 \mathrm{~min})$ to $250{ }^{\circ} \mathrm{C}(5 \mathrm{~min})$ at $5{ }^{\circ} \mathrm{C} \mathrm{min}{ }^{-1}$. As in previous works, ${ }^{2-4}$ the reactions of 4 with $\mathrm{Mg}$ (and with $t$-BuLi) were performed in a Schlenk tube equipped with greaseless stopcock and Teflon protected screw-cap. ${ }^{1} \mathrm{H}$ NMR and ${ }^{13} \mathrm{C}$ NMR were recorded with a Bruker Avance $300 \mathrm{MHz}$ spectrometer. Reaction mixtures were analyzed from 
${ }^{1} \mathrm{H}$ NMR, GC, GC-MS and by comparison with authentic samples. 1-bromo-2-(3butenyl)benzene $\mathbf{1}^{49 \mathrm{~b}}$ authentic samples of 3-butenylbenzene $\mathbf{2}^{49 \mathrm{~b}}$ and 1-methylindane $\mathbf{3}^{49 \mathrm{~b}, 52}$ were prepared as described in literature. An authentic sample of 3,4-diphenyl-1-butene 5 was prepared in diethyl ether from the Grignard reagent of 1-bromo-2-(2-phenyl-3-butenyl)benzene 4. The ${ }^{1} \mathrm{H}$ NMR and GC-MS data obtained agree with published values. ${ }^{53,54}$ 1-Methyl-2phenylindane $\mathbf{6}$ and (E)-1,2-diphenyl-2-butene $\mathbf{8}$ were isolated from reaction mixtures (see experimental part). 2-phenyltetralin $\mathbf{7}$ was isolated among other reaction products, this structure was proposed by NMR $\left({ }^{1} \mathrm{H},{ }^{13} \mathrm{C}\right)$ and GC-MS comparisons with literature and database data (NIST98.L). ${ }^{55,56}$

Preparation of 1-bromo-2-(2-phenyl-3-butenyl)benzene (4). A Schlenk tube containing 6.059 g $(249 \mathrm{mmol})$ of magnesium turnings was degassed by three cycles of vacuum-nitrogen. The metal was stirred for three days at room temperature under nitrogen. ${ }^{21}$ Then, another cycle vacuum-nitrogen was performed and the Schlenk tube was equipped with a dropping funnel containing a solution of cinnamyl bromide $(7.00 \mathrm{~g}, 35.5 \mathrm{mmol})$ in $\mathrm{Et}_{2} \mathrm{O}(66 \mathrm{~mL})$. The Schlenk tube was cooled with an ice bath and the solution was added dropwise over a 1.5-hour period. After this addition, the mixture was stirred for $2 \mathrm{~h}$ near $0{ }^{\circ} \mathrm{C}$. Then $1 \mathrm{~mL}$ of the Grignard reagent solution was titrated by the method of Watson and Eastham. ${ }^{57}$ The yield of Grignard reagent was ca $64 \%$. The Grignard reagent solution was transferred under nitrogen with a cannula, toward a two-necked flask containing 2-bromobenzyl bromide (2.27 g, $9.08 \mathrm{mmol})$ in $\mathrm{Et}_{2} \mathrm{O}(10 \mathrm{~mL})$. This flask was cooled with a $\mathrm{NaCl}$-ice bath. The reaction mixture was stirred overnight and reached room temperature. Then, the reaction mixture was quenched with $\mathrm{H}_{2} \mathrm{SO}_{4} 2 \mathrm{M}(8 \mathrm{~mL})$ and water $(2 \mathrm{~mL})$. After decantation and extraction with $\mathrm{Et}_{2} \mathrm{O}(2 \times 15 \mathrm{~mL})$, the organic layer was dried $\left(\mathrm{MgSO}_{4}\right)$. The solvent was evaporated and the crude product was purified on silica gel (petroleum ether as eluent) to give $1.377 \mathrm{~g}$ (53\% yield) of 1-bromo-2-(2-phenyl-3butenyl)benzene 4 as a colorless oil $\left(\geq 95 \%\right.$, GC) ${ }^{58}{ }^{1} \mathrm{H} \mathrm{NMR}\left(300 \mathrm{MHz}, \mathrm{CDCl}_{3}\right), \delta_{\mathrm{H}} 7.52(\mathrm{dd}, J$ $=7.9,1.5 \mathrm{~Hz}, 1 \mathrm{H}), 7.30-6.91(\mathrm{~m}, 8 \mathrm{H}), 6.07$ (ddd, $J=17.0,10.2,7.5 \mathrm{~Hz}, 1 \mathrm{H}), 5.03$ (ddd, $J=10.2$, $1.5,1.1 \mathrm{~Hz}, 1 \mathrm{H}), 4.95(\mathrm{dt}, J=17.0,1.5 \mathrm{~Hz}, 1 \mathrm{H}), 3.71($ broad q, $J=7.6 \mathrm{~Hz}, 1 \mathrm{H}), 3.18(\mathrm{dd}, J=$ $13.4,7.8 \mathrm{~Hz}, 1 \mathrm{H}), 3.08(\mathrm{dd}, J=13.4,7.4 \mathrm{~Hz}, 1 \mathrm{H}) .{ }^{13} \mathrm{C} \mathrm{NMR}\left(100 \mathrm{MHz}, \mathrm{CDCl}_{3}\right), \delta_{\mathrm{C}} 143.5,140.8$, 139.4, 132.8, 131.8, 128.5, 127.9, 127.8, 127.0, 126.5, 124.9, 115.2, 49.7, 42.6. Anal. Calcd. for $\mathrm{C}_{16} \mathrm{H}_{15} \mathrm{Br}$ : C, 66.91; H, 5.26. Found: C, 67.22; H, 5.36.

Reaction of 1-bromo-2-(2-phenyl-3-butenyl)benzene (4) with Bu3 $\mathrm{SnH}$. A solution of bromide $4(0.154 \mathrm{~g}, 0.536 \mathrm{mmol})$, AIBN $(0.0064 \mathrm{~g}, 0.039 \mathrm{mmol})$ and tributyltin hydride $(0.350 \mathrm{~mL}, 1.26$ mmol) in benzene $(4.65 \mathrm{~mL})$ was refluxed for $22 \mathrm{~h}$ under a nitrogen atmosphere. After evaporation of the solvent, $\mathrm{Et}_{2} \mathrm{O}(5 \mathrm{~mL})$ and $\mathrm{DBU}(0.3 \mathrm{~mL})$ were added and the mixture was titrated with a $0.1 \mathrm{M}$ iodine solution in $\mathrm{Et}_{2} \mathrm{O} .{ }^{59}$ The solution was filtered through a short column of silica gel, dried $\left(\mathrm{MgSO}_{4}\right)$ and evaporated. GC, GC-MS and NMR analyses of the reaction mixture showed the formation of products $\mathbf{5 , 6}$ and $\mathbf{7}$ in a ca $90 \%$ yield. The ratio 5/6/7 was 7/84/9. When 5 equiv of $\mathrm{Bu}_{3} \mathrm{SnH}(0.46 \mathrm{M})$ were used, the ratio 5/6/7 was 15/77/8. An authentic pure sample of the cyclized product (two diastereoisomers) was isolated from this experiment. A 
first chromatography on silica gel (petroleum ether and petroleum ether-ethyl acetate 95-5 as eluents) followed by a chromatography on $\mathrm{AgNO}_{3}$-impregnated silica gel (petroleum ether as eluent) afforded the rearranged product 6 (36\% isolated yield). The ratio trans/cis was $88 / 12 .{ }^{1} \mathrm{H}$ NMR (300 MHz, $\left.\mathrm{CDCl}_{3}\right), \delta_{\mathrm{H}}$ 7.34-7.14 (m, 9H cis- and 9H trans-), $3.76(\mathrm{q}, J=7.6 \mathrm{~Hz}, 1 \mathrm{H}$ cis-), 3.50 (quint., $J=7.4 \mathrm{~Hz}, 1 \mathrm{H}$ cis-), 3.33-3.03 (m, $4 \mathrm{H}$ trans- and $2 \mathrm{H}$ cis-), 1.29 (d, $J=6.6 \mathrm{~Hz}, 3 \mathrm{H}$ trans-), 0.85 (d, $J=7.4 \mathrm{~Hz}, 3 \mathrm{H}$ cis-). ${ }^{13} \mathrm{C} \mathrm{NMR}\left(75 \mathrm{MHz}, \mathrm{CDCl}_{3}\right), \delta_{\mathrm{C}} 148.55,147.48,144.00$, $142.74,142.55,142.38,128.59,128.32,128.23,127.85,126.73,126.72,126.64,126.57,126.55$, 126.28, 124.46, 124.27, 123.87, 123.23, 55.88, 49.59, 47.24, 43.90, 40.69, 36.51, 17.75, 16.25. GC-MS, $m / z$ (relative intensity): 208 (100), 193 (95), 179 (29), 178 (53), 130 (73), 117 (22), 115 (60), 91 (24). The stereochemistry of the two diastereoisomers was assigned by comparison with ${ }^{1} \mathrm{H}$ - and ${ }^{13} \mathrm{C}$ - NMR of the cis- isomer which were available in the literature. ${ }^{60,61}$

Reaction of 1-bromo-2-(2-phenyl-3-butenyl)benzene (4) with $\boldsymbol{t}$-BuLi. A Schlenk tube was successively degassed by three vacuum-nitrogen cycles, flamed under a flow of nitrogen and degassed again. Bromide $4(0.149 \mathrm{~g}, 0.52 \mathrm{mmol})$ and THF $(15 \mathrm{~mL})$ were added. The solution was cooled to $-78{ }^{\circ} \mathrm{C}$ (acetone-dry ice) and $t$ - $\mathrm{BuLi}(0.77 \mathrm{~mL}, 2.2$ equiv) was added. The solution was stirred $15 \mathrm{~min}$ at $-78{ }^{\circ} \mathrm{C}$ and $1 \mathrm{~h}$ without the cooling bath. The reaction mixture was quenched with water $(2 \mathrm{~mL})$, extracted with $\mathrm{Et}_{2} \mathrm{O}$ and dried $\left(\mathrm{MgSO}_{4}\right)$. GC, GC-MS and ${ }^{1} \mathrm{H} \mathrm{NMR}$ analyses show that the reaction mixture contains 5 and 8 in a 34/66 ratio. (E)-1,2-diphenyl-2butene $\mathbf{8}$ was isolated from the crude mixture. A first chromatography on silica gel (pentane as eluent) afforded a mixture of $\mathbf{8}$ and $\mathbf{5}$. A chromatography on $\mathrm{AgNO}_{3}$-impregnated silica gel was performed (pentane as eluent) to isolate the rearranged product $8\left(0.05 \mathrm{~g}, 46 \%\right.$ yield). ${ }^{1} \mathrm{H}$ NMR (300 MHz, $\left.\mathrm{CDCl}_{3}\right), \delta_{\mathrm{H}} 7.32-7.11(\mathrm{~m}, 10 \mathrm{H}), 6.08$ (q, J=6.8 Hz, 1H), $3.88(\mathrm{~s}, 2 \mathrm{H}), 1.85$ (d, $J=6.8 \mathrm{~Hz}, 3 \mathrm{H})$. This ${ }^{1} \mathrm{H}$ NMR spectrum was consistent with the $E$ stereochemistry. ${ }^{62,63}{ }^{13} \mathrm{C}$ NMR (75 MHz, $\left.\mathrm{CDCl}_{3}\right), \delta_{\mathrm{C}} 143.22,139.93,138.54,128.51,128.30,128.28,126.65,126.27$, 125.93, 125.07, 35.64, 14.73. GC-MS, m/z (relative intensity) : 208 (100), 193 (66), 179 (31), 178 (31), 130 (41), 117 (54), 115 (87), 91 (42).

This reaction was not controlled easily and revealed a capricious behavior. The best reproducibility was obtained using Schlenk techniques as described above. Nevertheless, variable amounts of two other products $\mathbf{9 a}$ and $\mathbf{9 b}$ were obtained $(\leq 1-20 \%)$ altering the ratio $\mathbf{5 / 8}$. These products were not isolated but GC-MS (molecular ion: $m / z=264$ ) and ${ }^{1} \mathrm{H}$ NMR (two singlets at 0.94 and $0.97 \mathrm{ppm}$ ) analyses of the crude product suggest that they probably result from the incorporation of the tert-butyl group. The ratio $\mathbf{5 / 8}$ became $48 / 52$ when $20 \%$ of tertbutyl incorporation was found $(\mathbf{5} / \mathbf{8} / \mathbf{9} \mathbf{a}-\mathbf{b}=38 / 42 / 20)$.

Reaction of 1-bromo-2-(2-phenyl-3-butenyl)benzene (4) with Mg. Magnesium (0.0322 g, 1.32 mmol) was introduced in a Schlenk tube equipped with a magnetic bar. The Schlenk tube was successively degassed by three cycles of vacuum/nitrogen, flamed under a flow of nitrogen and degassed again. A flask (10 mL) containing bromide $4(0.0857 \mathrm{~g}, 0.298 \mathrm{mmol})$, was flushed with nitrogen for about $10 \mathrm{~min}$. Then, THF ( $2 \mathrm{~mL})$ and 1,2-dibromoethane (10 $\mu \mathrm{l}, 0.115 \mathrm{mmol})$ were added by syringe in the flask. The solution obtained was transferred via cannula to the Schlenk tube. After 3 h $20 \mathrm{~min}$ of stirring (Teflon coated stir bars were used) at room temperature the 
yield of the Grignard reagent was estimated by the Watson and Eastham's method. ${ }^{57}$ A solution of $o$-phenanthroline $(\sim 1 \mathrm{mg})$ in THF $(\sim 1 \mathrm{~mL})$ was added by syringe. If the Grignard reagent is present, a red-maroon color develops here. The mixture was then titrated to the endpoint with a solution of 2-butanol in xylenes $(0.5 \mathrm{M})$. The yield was $89 \%$ (average of 2 experiments). After dilution with $\mathrm{Et}_{2} \mathrm{O}$, the reaction mixture was successively washed with ammonium chloride $10 \%$ and water, dried $\left(\mathrm{MgSO}_{4}\right)$, and filtered. GC and ${ }^{1} \mathrm{H}$ NMR analyses show that the reaction mixture contains $\mathbf{5}$ and $\mathbf{8}$ in a 91/9 ratio.

\section{References}

1. Chanon, M.; Négrel, J.-C.; Bodineau, N.; Mattalia, J.-M.; Péralez, E. Macromol. Symp. 1998, 134, 13.

2. Bodineau, N.; Mattalia, J.-M.; Timokhin, V.; Handoo, K.; Négrel, J.-C.; Chanon, M. Org. Lett. 2000, 2, 2303.

3. Hazimeh, H.; Mattalia, J.-M.; Marchi-Delapierre, C.; Barone, R.; Nudelman, N. S.; Chanon, M. J. Phys. Org. Chem. 2005, 18, 1145.

4. Hazimeh, H.; Mattalia, J. M.; Marchi-Delapierre, C.; Kanoufi, F.; Combellas, C.; Chanon, M. Eur. J. Org. Chem. 2009, 2775.

5. Garden, S. J.; Avila, D. V.; Beckwith, A. L. J.; Bowry, V. W.; Ingold, K. U.; Lusztyk, J. J. Org. Chem. 1996, 61, 805.

6. Johnston, L. J.; Lusztyk, J.; Wayner, D. D. M.; Abeywickreyma, A. N.; Beckwith, A. L. J.; Scaiano, J. C.; Ingold, K. U. J. Am. Chem. Soc. 1985, 107, 4594.

7. Annunziata, A.; Galli, C.; Marinelli, M.; Pau, T. Eur. J. Org. Chem. 2001, 1323.

8. Branchi, B.; Galli, C.; Gentili, P. Eur. J. Org. Chem. 2002, 2844.

9. Ross, G. A.; Koppang, M. D.; Bartak, D. E.; Woolsey, N. F. J. Am. Chem. Soc. 1985, 107, 6742.

10. Koppang, M. D.; Ross, G. A.; Woolsey, N. F.; Bartak, D. E. J. Am. Chem. Soc. 1986, 108, 1441.

11. Meijs, G. F.; Bunnett, J. F.; Beckwith, A. L. J. J. Am. Chem. Soc. 1986, 108, 4899.

12. Bowry, V. W.; Ingold, K. U. J. Am. Chem. Soc. 1991, 113, 5699.

13. Newcomb, M.; Chestney, D. L. J. Am. Chem. Soc. 1994, 116, 9753.

14. Newcomb, M.; Shen, R.; Choi, S.-Y.; Toy, P. H.; Hollenberg, P. F.; Vaz, A. D. N.; Coon, M. J. J. Am. Chem. Soc. 2000, 122, 2677.

15. Drozd, V. N.; Ustynyuk, Y. A.; Tsel'eva, M. A.; Dmitriev, L. B. J. Zh. Obsch. Khim. 1969, 39, 1991.

16. Lusztyk, J.; Maillard, B.; Deycard, S.; Lindsay, D. A.; Ingold, K. U. J. Org. Chem. 1987, 52, 3509.

17. Bailey, W. F.; Patricia, J. J. J. Organomet. Chem. 1988, 352, 1.

18. Garst, J. F.; Hines, J. B. J. Am. Chem. Soc. 1984, 106, 6443. 
19. Cohen, T.; Gibney, H.; Ivanov, R.; Yeh, E. A.-H.; Marek, I.; Curran, D. P. J. Am. Chem. Soc. 2007, 129, 15405.

20. Newcomb, M. Acta Chem. Scand. 1990, 44, 299.

21. Baker, K. V.; Brown, J. M.; Hughes, N.; Skarnulis, A. J.; Sexton, A. J. Org. Chem. 1991, 56, 698.

22. Benkeser, R. A. Synthesis 1971, 347.

23. Chatgilialoglu, C. In Radicals in Organic Synthesis; Renaud, P. S., Sibi, M.P., Eds.; WileyVCH: Weinheim, 2001; Vol. 1, p 28.

24. Brocks, J. J.; Beckhaus, H.-D.; Beckwith, A. L. J.; Rüchardt, C. J. Org. Chem. 1998, 63, 1935.

25. Clark, K. B.; Culshaw, P. N.; Griller, D.; Lossing, F. P.; Simões, J. A. M.; Walton, J. C. J. Org. Chem. 1991, 56, 5535.

26. Curran, D. P.; Yang, F.; Cheong, J. J. Am. Chem. Soc. 2002, 124, 14993.

27. Journet, M.; Malacria, M. Tetrahedron Lett. 1992, 33, 1893.

28. Gulea, M.; López-Romero, J. M.; Fensterbank, L.; Malacria, M. Org. Lett. 2000, 2, 2591.

29. Beckwith, A. L. J.; Gerba, S. Austral. J. Chem. 1992, 45, 289.

30. Abeywickrema, A. N.; Beckwith, A. L. J.; Gerba, S. J. Org. Chem. 1987, 52, 4072.

31. Abeywickrema, A. N.; Beckwith, A. L. J. J. Chem. Soc., Chem. Commun. 1986, 464.

32. This value could be inaccurate. A series of competition reactions which the concentration of $\mathrm{Bu}_{3} \mathrm{SnH}$ varies are necessary when precise values are desired: Newcomb, M. Tetrahedron 1993, 49, 1151.

33. Magid, R. M.; Wilson, S. E. Tetrahedron. Lett. 1971, 12, 19.

34. Seebach, D.; Neumann, H. Chem. Ber. 1974, 107, 847.

35. Bailey, W. F.; Patricia, J. J.; Nurmi, T. T.; Wang, W. Tetrahedron Lett. 1986, 27, 1861.

36. Boatman, R. J.; Whitlock, B. J.; Whitlock, H. W. J. Am. Chem. Soc. 1977, 99, 4822.

37. Taylor, E. C.; Vogel, D. E. J. Org. Chem. 1985, 50, 1002.

38. Orito, K.; Miyazawa, M.; Suginome, H. Tetrahedron 1995, 51, 2489.

39. Stein, C. A.; Morton, T. H. Tetrahedron Lett. 1973, 14, 4933.

40. Beak, P.; Musick, T. J.; Liu, C.; Cooper, T.; Gallagher, D. J. J. Org. Chem. 1993, 58, 7330 and references cited therein.

41. Bailey, W. F.; Carson, M. W. Tetrahedron Lett. 1997, 38, 1329.

42. Garst, J. F.; Pacifici, J. A.; Felix, C. C.; Nigam, A. J. Am. Chem. Soc. 1978, 100, 5974.

43. Menger, F. M. Acc. Chem. Res. 1985, 18, 128.

44. Karaman, R. Tetrahedron Lett. 2010, 51, 2130.

45. Bickelhaupt, F.; Newcomb, M.; DeZutter, C. B.; de Boer, H. J. R. Eur. J. Org. Chem. 2008, 6225.

46. Bickelhaupt, F. J. Organomet. Chem. 1994, 475, 1.

47. van Klink, G. P. M.; de Boer, H. J. R.; Schat, G.; Akkerman, O. S.; Bickelhaupt, F.; Spek, A. L. Organometallics 2002, 21, 2119. 
48. Markies, P. R.; Akkerman, O. S.; Bickelhaupt, F.; Smeets, W. J. J.; Spek, A. L. J. Am. Chem. Soc. 1988, 110, 4284.

49. For another interpretation involving carbanion intermediates see (a) Garst, J. F.; Soriaga, M. R. Coord. Chem. Rev. 2004, 248, 623. (b) Garst, J. F.; Boone, J. R.; Webb, L.; Lawrence, K. E.; Baxter, J. T.; Ungváry, F. Inorg. Chim. Acta 1999, 296, 52.

50. Garst, J. F.; Ungváry, F. In Grignard Reagents: New Developments; Richey, H. G., Jr., Ed.; Wiley: Chichester, 2000, p. 185.

51. Scanlon, J. T.; Willis, D. E. J. Chromatogr. Sci. 1985, 23, 333.

52. Adamczyk, M.; Watt, D. S.; Netzel, D. A. J. Org. Chem. 1984, 49, 4226.

53. Wylie, P. L.; Prowse, K. S.; Belill, M. A. J. Org. Chem. 1983, 48, 4022.

54. Evans, P. A.; Uraguchi, D. J. Am. Chem. Soc. 2003, 125, 7158.

55. Jung, M. E.; Mossman, A. B.; Lyster, M. A. J. Org. Chem. 1978, 43, 3698.

56. Tuschka, T.; Naito, K.; Rickborn, B. J. Org. Chem. 1983, 48, 70.

57. Watson, S. C.; Eastham, J. F. J. Organomet. Chem. 1967, 9, 165.

58. Only isolated compound 4 judged to be $\geq 95 \%$ pure was used and, if necessary, another column chromatography using $\mathrm{AgNO}_{3}$-impregnated silica gel was performed.

59. Curran, D. P.; Chang, C.-T. J. Org. Chem. 1989, 54, 3140.

60. Troutman, M. V.; Appella, D. H.; Buchwald, S. L. J. Am. Chem. Soc. 1999, 121, 4916.

61. Schrems, M. G.; Neumann, E.; Pfaltz, A. Angew. Chem. Int. Ed. 2007, 46, 8274.

62. James, B. G.; Pattenden, G. J. Chem. Soc., Perkin Trans. 1 1974, 1204.

63. Millard, B. J.; Sheinin, E. B.; Benson, W. R. J. Pharm. Sci. 1980, 69, 1177. 